\title{
Effect of Cerebral Hypothermia on Cortisol and Adrenocorticotropic Hormone Responses after Umbilical Cord Occlusion in Preterm Fetal Sheep
}

\author{
JOANNE O. DAVIDSON, MHOYRA FRASER, ANDREW S. NAYLOR, VINCENT ROELFSEMA, ALISTAIR J. GUNN,
} AND LAURA BENNET Department of Physiology [J.O.D., A.S.N., V.R., A.J.G., L.B.], The Liggins Institute [M.F.], The University of Auckland, Auckland 1023,
New Zealand

\begin{abstract}
The hypothalamic-pituitary-adrenal (HPA) axis is essential for adaptation to stress. In the present study, we examined the hypothesis that head cooling with mild systemic hypothermia would adversely affect fetal adrenocorticotropic hormone (ACTH) and cortisol responses to an asphyxial insult. Chronically instrumented preterm fetal sheep ( $104 \mathrm{~d}$ of gestation, term is $147 \mathrm{~d}$ ) were allocated to sham occlusion $(n=7), 25$ min of complete umbilical cord occlusion $(n=7)$, or occlusion and head cooling with mild systemic hypothermia $(n=7$, mean \pm SEM esophageal temperature $37.6 \pm$ $0.3^{\circ} \mathrm{C}$ vs $\left.39.0 \pm 0.2^{\circ} \mathrm{C} ; p<0.05\right)$ from $90 \mathrm{~min}$ to $70 \mathrm{~h}$ after occlusion, followed by spontaneous rewarming. During umbilical cord occlusion, there was a rapid rise in ACTH and cortisol levels, with further increases after release of cord occlusion. ACTH levels returned to sham control values after $10 \mathrm{~h}$ in both occlusion groups. In contrast, plasma cortisol levels remained elevated after $48 \mathrm{~h}$ in both occlusion groups and were still significantly elevated in the hypothermia-occlusion group $2 \mathrm{~h}$ after rewarming, at $72 \mathrm{~h}$, compared with the normothermia-occlusion and sham groups. In conclusion, hypothermia does not affect the overall HPA responses to severe asphyxia in the preterm fetus but does prolong the cortisol response. (Pediatr Res 63: 51-55, 2008)
\end{abstract}

$\mathrm{T}$ here is now strong clinical and experimental evidence that a prolonged period of moderate cerebral hypothermia initiated within a few hours after severe hypoxia-ischaemia can reduce subsequent neuronal loss and improve behavioral recovery in adults and term newborn infants (1). Preterm infants have a much higher burden of neurologic impairment (2). Although the etiology of preterm injury is multifactorial, exposure to hypoxia as shown by metabolic acidosis, active labor, abnormal heart rate traces in labor, and subsequent low Apgar scores is an important factor associated with adverse outcomes (3-6), raising the possibility that some preterm infants might be candidates for treatment (7). However, despite the remarkable safety record of hypothermia so far in term infants, older clinical evidence suggests increased mortality in preterm infants $(<1500 \mathrm{~g})$ exposed to even mild systemic hypothermia $(8-10)$.

Received June 26, 2007; accepted August 9, 2007.

Correspondence: Laura Bennet, Ph.D., Department of Physiology, Faculty of Medicine and Health Science, The University of Auckland, Private Bag 92019, Auckland 1023, New Zealand; e-mail: 1.bennet@ auckland.ac.nz

This study was supported by the Health Research Council of New Zealand, Auckland Medical Research Foundation, and the Lottery Grants Board of New Zealand.
In the first few days after birth, premature infants commonly have unstable arterial blood pressure, and, in turn, exposure to severe hypotension is associated with adverse outcomes $(11,12)$. The hypothalamic-pituitary-adrenal (HPA)mediated increase in cortisol during severe stress is essential to maintain blood pressure, and there is evidence that abnormal HPA function in some preterm infants is associated with cardiovascular compromise $(13,14)$. The effect of hypothermia on the HPA responses of preterm infants is unknown. Mild hypothermia during cerebral aneurysm surgery has been associated with a significant decrease in plasma levels of cortisol and adrenocorticotropic hormone (ACTH) at extubation (15) that potentially might compromise cardiovascular adaptation. Conversely, hypothermia might cause an excessive HPA response; for example, data in term piglets suggest that induced hypothermia during recovery from severe hypoxia-ischemia without sedation was associated with an excessive rise in plasma cortisol levels that may reduce its neuroprotective effects (16). However, there are no data from preterm paradigms. We have recently reported that, consistent with the data at older ages, cerebral cooling with mild systemic hypothermia markedly reduces loss of immature oligodendroglia and neurons after a period of asphyxia in the preterm fetal sheep $(17,18)$, with a mild bradycardia compared with normothermia but without hypotension (17). Central cooling was sustained for $72 \mathrm{~h}$ but was milder than typically used during clinical cooling in term infants (19). In this paradigm, asphyxia has been associated with prolonged elevation of plasma cortisol levels, sustained for $48 \mathrm{~h}$ after occlusion (20). The effect of hypothermia on this response is unknown. We therefore examined the hypothesis that hypothermia after profound hypoxia induced by umbilical cord occlusion in unanesthetized preterm fetal sheep at 0.7 of gestation (term $147 \mathrm{~d}$ gestation) would be associated with an impaired HPA response.

\section{MATERIALS AND METHODS}

Experimental preparation. All procedures were approved by the Animal Ethics Committee of The University of Auckland. Twenty-one time-mated

Abbreviations: HPA, hypothalamic-pituitary-adrenal; PGE2, prostaglandin E2 
singleton Romney/Suffolk fetal sheep were instrumented at 97-99 d of gestation (term $=147 \mathrm{~d}$ ) under general anesthesia $\left(2 \%\right.$ halothane in $\mathrm{O}_{2}$ ). Although the sheep is relatively precocial compared with humans, this age is neurodevelopmentally equivalent to the human fetus of approximately 30-32 wk of gestation, before the onset of cortical myelination $(21,22)$, and the adrenal gland is immature (23). We have previously reported changes in white and grey matter cell loss, cardiovascular variables, arterial $\mathrm{pH}$, blood gases, and plasma levels of glucose and lactate in these fetuses $(17,24)$. Details of anesthetic and fluid management, the sterile surgical preparation, intraoperative and postoperative antibiotic prophylaxis, and management have been described in detail previously (17).

Fetal catheters were placed in the left femoral artery and vein, right brachial artery and vein, and the amniotic sac. Two pairs of electroencephalogram electrodes (AS633-5SSF, Cooner Wire Co., Chatsworth, CA) were placed on the dura over the parasagittal parietal cortex $(5 \mathrm{~mm}$ and $15 \mathrm{~mm}$ anterior to bregma and $10 \mathrm{~mm}$ lateral), with a reference electrode sewn over the occiput. A thermistor (Incutemp-1, Mallinckrodt Medical, Inc., St. Louis, MO) was placed over the parasagittal dura $20 \mathrm{~mm}$ anterior to bregma to measure extradural temperature, and the burr holes were sealed and the skin over the fetal skull secured with cyanoacrylate glue. Electrocardiogram electrodes were sewn across the chest to record the fetal heart rate (FHR). A second thermistor (to measure fetal core body temperature) was placed in the fetal esophagus at the level of the right atrium. An inflatable silicone occluder was placed around the umbilical cord of all fetuses (In Vivo Metric, Healdsburg, CA). A cooling coil made from silicone tubing (external diameter 7.9 $\mathrm{mm}$, internal diameter $4.8 \mathrm{~mm}$; Silclear, Degania Silicone, Degania Bet, Israel) was attached over the dorsal surface of the scalp and extended over the lateral surface of the cranium down to the level of the external auditory meatus. All fetal catheters and leads were exteriorized through the maternal flank, and the maternal skin incision was infiltrated with the long-acting local anesthetic Marcain (bupivacaine hydrochloride $0.25 \%$ with adrenaline 1:400,000; Astra Zeneca, North Ryde, NSW, Australia).

After surgery, sheep were housed together in separate metabolic cages with access to water and food as desired. A period of $4-5 \mathrm{~d}$ of postoperative recovery was allowed before starting experiments. The health and welfare of all animals was closely monitored by the researchers and supervised by the university veterinarian. Fetal brachial arterial blood was taken daily for gas analysis. Catheters were maintained patent by continuous infusion of heparinized isotonic saline $\left(20 \mathrm{U} \mathrm{ml}^{-1}, 0.2 \mathrm{~mL} \mathrm{~h}^{-1}\right)$.

Experimental design and recordings. Experiments were conducted at 103-104 d gestation. Fetuses were randomly assigned to either normothermia-occlusion $(n=7)$, hypothermia-occlusion $(n=7)$, or normothermia-sham occlusion (sham control, $n=7$ ) groups. Fetal asphyxia was induced in both occlusion groups by rapid inflation of the umbilical cord occluder for $25 \mathrm{~min}$ with sterile saline of a defined volume known to completely inflate the occluder (17). Successful occlusion was confirmed by observation of a rapid onset of bradycardia with a rise in mean arterial blood pressure (MAP) and by $\mathrm{pH}$ and blood gas measurements. In all groups, fetal arterial blood was taken at $15 \mathrm{~min}$ before occlusion, 20 min during occlusion, and $30 \mathrm{~min}, 2 \mathrm{~h}, 6 \mathrm{~h}, 24 \mathrm{~h}, 48 \mathrm{~h}$, and $72 \mathrm{~h}$ postocclusion for blood gas, acid-base balance (Ciba-Corning Diagnostics 845 blood gas analyzer and co-oximeter, East Walpole, MA), glucose, and lactate determination (YSI model 2300, Yellow Springs, OH), and ACTH and cortisol measurements. Intrauterine cooling was performed from $90 \mathrm{~min}$ to $70 \mathrm{~h}$ after the end of occlusion. In the hypothermia group, the $72 \mathrm{~h}$ blood sample was taken after rewarming for $2 \mathrm{~h}$. Cooling was induced by circulating cold water $\left(10^{\circ} \mathrm{C}\right)$ through a coil around the fetal head. Cooling was titrated in the first $2 \mathrm{~h}$ to reduce fetal extradural temperature from $39.4 \pm 0.1^{\circ} \mathrm{C}$ to less than $34^{\circ} \mathrm{C}$. At $72 \mathrm{~h}$ after the end of occlusion, the ewes and fetuses were killed by an overdose of sodium pentobarbitone $(9 \mathrm{~g}$ intravenously to the ewe, Pentobarb 300 , Chemstock International, Christchurch, New Zealand), and fetal adrenal weights were measured postmortem.

Hormone analysis. Fetal plasma ACTH and cortisol levels were measured using specific radioimmunoassays (RIA) established and validated for ovine plasma (25). Total immunoreactive cortisol concentrations were determined in triplicate after extraction with diethyl ether by an in-house RIA validated for use with maternal and fetal ovine plasma. The antiserum to cortisol was raised in rabbits against Cortisol 3-CMO:bovine serum albumin and was used at a final dilution of 1:19200. The cross-reactivity of the antiserum at 50\% binding with other relevant steroid-related compounds was $3.3 \%$ 11deoxycortisol, $0.18 \%$ cortisone, $0.5 \%$ corticosterone, $0.015 \%$ progesterone, and $0.002 \% 11 \alpha$-hydroxyprogesterone. No detectable cross-reactivity was observed for $17 \alpha$-hydroxypregnenolone, pregnanediol, 21-deoxycortisone, aldosterone, cholesterol, or dexamethasone. The lower limit of detection was $10 \mathrm{pg} /$ tube $(0.13 \mathrm{ng} / \mathrm{mL})$; samples containing less than $0.13 \mathrm{ng} / \mathrm{mL}$ were given this value for the purposes of analysis. The intra- and interassay coefficients of variations were $3.68 \%$ and $3.97 \%$, respectively, at the cortisol concentrations determined in plasma.

Immunoreactive concentrations of ACTH were measured in duplicate using a commercially available ${ }^{125}$ I RIA kit (24130, DiaSorin, Stillwater, MN) previously validated for use with both fetal and maternal ovine plasma. The intra-assay and interassay coefficient of variation were $9.7 \%$ and $12.8 \%$, respectively. The mean sensitivity of the ACTH assay was $9.7 \mathrm{pg} / \mathrm{mL}$; samples containing less than $9.7 \mathrm{pg} / \mathrm{mL}$ were given this value for analysis.

Data analysis and statistics. Offline analysis of the physiologic data were performed using customized Labview programs (Labview, National Instruments, Austin, TX). The effect of occlusion was evaluated by analysis of variance (ANOVA; SPSS v12, SPSS, Inc., Chicago, IL). The baseline period was taken as the mean of the samples before occlusion. Differences between groups were determined by ANOVA adjusted using baseline levels as a covariate. Where a significant effect of treatment group or an interaction between time and group was found, post hoc comparisons were undertaken using the least significant difference test. Statistical significance was accepted at $p<0.05$. Data are mean \pm SEM.

\section{RESULTS}

Data for arterial $\mathrm{pH}$, blood gases, glucose, lactate, FHR, and MAP for all groups are presented in Table 1. Occlusion of the umbilical cord was associated with marked fetal hypoxia and acidosis, bradycardia, and hypotension (Table 1) $(p<0.001)$, as previously reported (17). After reperfusion, there was rapid recovery of FHR and MAP. MAP was significantly higher at 2-6 $\mathrm{h}$ after occlusion in the normothermia-occlusion group compared with sham controls (Table 1) ( $p<0.005$, ANOVA) and returned to sham control values by $24 \mathrm{~h}$. In the hypothermia-occlusion group, MAP was intermediate between the sham controls and the normothermia-occlusion group and not significantly different from normothermia occlusion. FHR was significantly lower in the normothermia-occlusion group than sham controls from 24 to $72 \mathrm{~h}$. FHR was transiently lower in the hypothermia-occlusion group than the normothermiaocclusion group from $4 \mathrm{~h}$ to $6 \mathrm{~h}$ and lower than in sham controls from 4 to $48 \mathrm{~h}$ after occlusion but returned to sham control values by $72 \mathrm{~h}$.

Brain and body temperature. Head cooling was initiated 90 min after the end of the umbilical cord occlusion and was associated with a significant fall in extradural and esophageal temperatures starting within an hour after the onset of cooling (17). The mean extradural temperature during cooling was $31.0 \pm 0.8^{\circ} \mathrm{C}$ (versus $39.4 \pm 0.2^{\circ} \mathrm{C}$ normothermia occlusion, $p<0.001)$, and the mean esophageal temperature was $37.6 \pm$ $0.3^{\circ} \mathrm{C}$ (versus $39.0 \pm 0.2^{\circ} \mathrm{C}, p<0.001$ ).

ACTH and cortisol. There were no significant baseline differences in ACTH or cortisol levels between the groups. After $20 \mathrm{~min}$ of occlusion, there was a significant rise in plasma concentrations of both ACTH $(p<0.05$, ANOVA) and cortisol $(p<0.05)$ in both occlusion groups compared with sham controls. After reperfusion, plasma ACTH levels remained significantly elevated for the first $24 \mathrm{~h}$ after occlusion, peaking between 2 and $4 \mathrm{~h}$ in both the normothermia and hypothermia groups (Fig. 1). There were no significant differences in the ACTH responses of the normothermia-occlusion and hypothermia-occlusion groups (ANOVA). Plasma cortisol levels peaked at $6 \mathrm{~h}$ after occlusion in both the normothermia and hypothermia groups $(p<0.05)$ (Fig. 1) and remained significantly elevated compared with sham controls until $48 \mathrm{~h}$ after occlusion. Mild systemic hypothermia did not significantly affect the response to occlusion in the first $48 \mathrm{~h}$; 
Table 1. Fetal arterial pH, blood gas, glucose and lactate values for sham control (S), normothermia-occlusion (N), and hypothermia-occlusion (H) groups before a $25 \mathrm{~min}$ period of umbilical cord occlusion (baseline), at 20 min of occlusion or sham occlusion (occlusion), and 2, 4, 6, 24, 48, and $72 \mathrm{~h}$ after occlusion

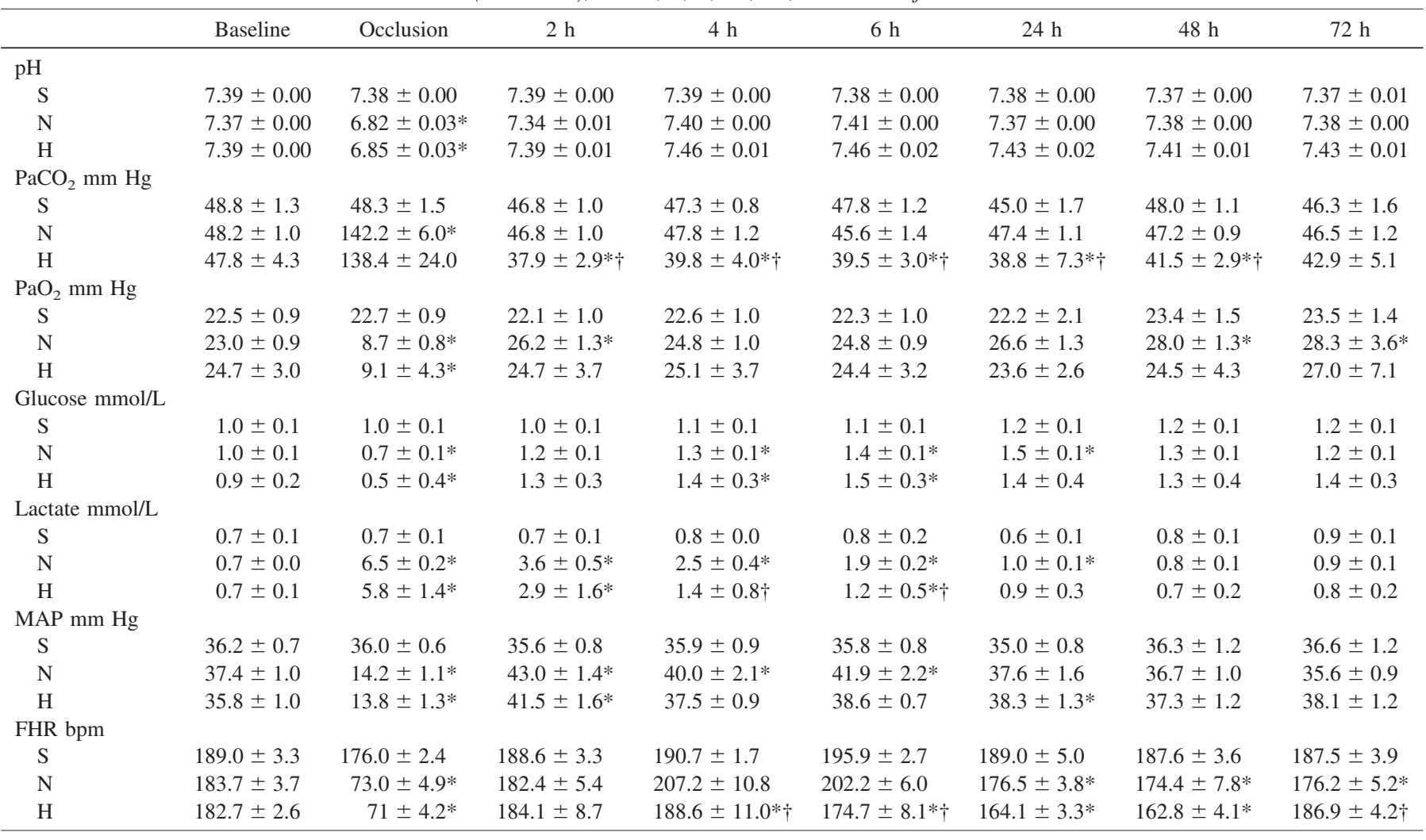

Values are mean \pm SEM.

MAP and FHR values before and after occlusion or sham occlusion are hourly averages; values at 20 min of occlusion are 1 min averages.

$* p<0.05$ compared with sham control; $\dagger p<0.05$ compared with normothermia occlusion.

however, cortisol levels were significantly greater at $72 \mathrm{~h}$ than in either the sham control or normothermia-occlusion groups $(p<0.05$, ANOVA).

Adrenal weight. There was no overall effect of group on mean adrenal weight at postmortem $(p=0.1$, one way ANOVA): sham controls $0.10 \pm 0.01 \mathrm{mg}$, normothermia occlusion $0.11 \pm 0.01 \mathrm{mg}$, hypothermia occlusion $0.13 \pm 0.01 \mathrm{mg}$.

\section{DISCUSSION}

The HPA responses to stress are critical for newborn adaptation. In preterm infants, there is evidence that cortisol levels are significantly correlated with the lowest blood pressure in the immediate postnatal period (14), and at least some infants with refractory hypotension have adrenocortical insufficiency that is responsive to exogenous steroid therapy $(13,14)$. The present study demonstrates that cerebral hypothermia with mild systemic cooling after severe hypoxia neither suppressed the HPA response nor triggered an exaggerated rise in cortisol. Consistent with our previous report (20), occlusion led to a robust, prolonged ACTH and cortisol response that continued well after the end of occlusion. Hypothermia started after the occlusion period did not affect either the ACTH or cortisol response in the first $48 \mathrm{~h}$ after occlusion but was associated with a small increase in cortisol, but not ACTH levels, $72 \mathrm{~h}$ after asphyxia compared with normothermia.
Concern that hypothermia after hypoxic-ischemic injury might adversely affect HPA responses was raised by a study in which moderate whole-body cooling was not protective in the unanesthetized piglets after an hypoxic-ischemic event, and cooling was associated with increased cortisol levels (16). There is evidence that blockade of the glucocorticoid receptor after ischemia in adult rodents can at least transiently improve neuronal survival (26), and thus an exaggerated cortisol response might well impair hypothermic protection. In contrast, the present study suggests that a known protective interval of hypothermia (17) had only a very small effect on the HPA axis. Partly, this may be because the degree of central cooling in the present study was relatively mild, with less than a $2^{\circ} \mathrm{C}$ fall in central temperature compared with $4^{\circ} \mathrm{C}$ in the piglets (16); this is also somewhat less than currently used during clinical head cooling (a mean reduction of $2.5^{\circ} \mathrm{C}$ ) (19). Potentially, it might reflect higher levels of circulating inhibitory neuromodulators such as adenosine, which could attenuate stress experienced by the fetus (27). Against this possibility, the HPA response to asphyxia in the present study was very marked, with a relative rise greater than that reported after a severe hypoxic insult in the piglet (16).

In part, it likely also reflects the global asphyxial insult used in the present study and correspondingly much more severe cardiovascular impact (28) than seen in the neonatal piglet 

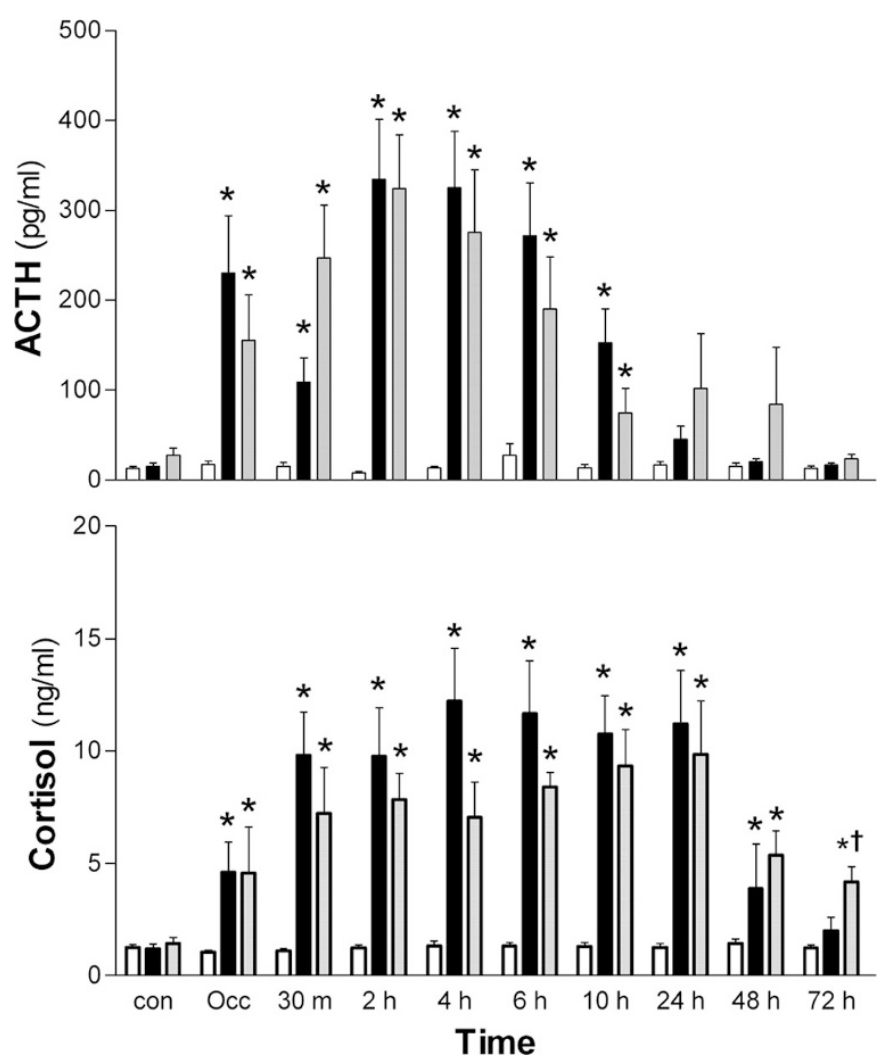

Figure 1. Time sequence of changes in fetal plasma ACTH (top) and cortisol levels (bottom) before, during, and after sham occlusion (open bars) or $25 \mathrm{~min}$ of occlusion of the umbilical cord followed by normothermia (black bars, normothermia occlusion) or head cooling with mild systemic hypothermia from $90 \mathrm{~min}$ to $70 \mathrm{~h}$ after occlusion (grey bars, hypothermia occlusion). Occ, $20 \mathrm{~min}$ of occlusion; $30 \mathrm{~m}, 30 \mathrm{~min}$ after occlusion. Data are mean \pm SEM. $* p<0.05$ vs sham control. $\dagger p<0.05$ vs normothermia occlusion.

model of controlled hypoxia and hypotension (29). We have previously reported that peripheral vascular resistance was increased after umbilical cord occlusion in preterm fetal sheep and that cortisol levels during this time were correlated positively with MAP (20), suggesting that the cortisol response was at least partly contributing to maintenance of blood pressure at a time when cardiac function was impaired after hypoxia. Thus, we may speculate that the effect of hypothermia on the HPA axis may have been masked in the first $48 \mathrm{~h}$ by much stronger stimuli consequent to profound asphyxia.

The early rises in ACTH and cortisol in the present study suggest an initial ACTH driven response. In contrast, at 24 and $48 \mathrm{~h}$ after hypoxia, cortisol levels were dissociated from those of ACTH, remaining significantly elevated well after ACTH levels had returned to sham control levels (20). In the hypothermia group, cortisol levels were still elevated $2 \mathrm{~h}$ after rewarming at $72 \mathrm{~h}$ compared with sham controls. Although there was a trend for slower resolution of the postasphyxial rise in ACTH during cooling, by $72 \mathrm{~h}$ after the end of occlusion, ACTH values were not different from sham controls. A potential limitation is that we do not know whether ACTH was elevated at $70 \mathrm{~h}$, before rewarming. However, because cortisol levels were still elevated, this is suggestive of an ACTH-independent adrenal response, as reported during chronic hypoxia $(30,31)$. These data suggest for the first time that hypothermia may also trigger such a response in the preterm fetus.

Potential mechanisms might include increased sympathetic activity (32), with activation of the splanchnic nerve (33), or increased levels of other steroidogenic factors, including the neuropeptides and prostaglandin E2 (PGE2) (31). Although endogenous and exogenous PGE2 substantially increase cortisol levels, this effect is primarily mediated through hypothalamic ACTH release (34). However, there is some in vitro evidence of a paracrine effect of PGE2 to sensitize adrenal cells to ACTH stimulation in preterm fetal sheep (35). Alternatively, it might potentially reflect slower clearance of cortisol during cooling; however, postnatal data suggest that clearance is only delayed by significantly greater falls in rectal temperature than in the present study (36). Finally, there is evidence that chronic hypoxia can increase the size and enzymatic activity of the adrenal gland $(31,37)$. Thus, potentially, the delayed fall in cortisol levels could reflect local adrenal up-regulation. However, although there was a trend to increased adrenal weight after hypothermia compared with sham controls in the present study, with intermediate values in the normothermia-occlusion group, there was no significant overall effect. In conclusion, the present study suggests that hypothermia does not adversely affect the prolonged upregulation of HPA activity seen after profound reversible asphyxia in preterm fetal sheep.

\section{REFERENCES}

1. Gunn AJ, Thoresen M 2006 Hypothermic neuroprotection. NeuroRx 3:154-169

2. Sweet MP, Hodgman JE, Pena I, Barton L, Pavlova Z, Ramanathan R 2003 Two-year outcome of infants weighing 600 grams or less at birth and born 1994 through 1998. Obstet Gynecol 101:18-23

3. Low JA, Panagiotopoulos C, Derrick EJ 1995 Newborn complications after intrapartum asphyxia with metabolic acidosis in the preterm fetus. Am J Obstet Gynecol 172:805-810

4. Weinberger B, Anwar M, Hegyi T, Hiatt M, Koons A, Paneth N 2000 Antecedents and neonatal consequences of low Apgar scores in preterm newborns: a population study. Arch Pediatr Adolesc Med 154:294-300

5. Osborn DA, Evans N, Kluckow M 2003 Hemodynamic and antecedent risk factor of early and late periventricular/intraventricular hemorrhage in premature infants. Pediatrics 112:33-39

6. de Vries LS, Eken P, Groenendaal F, Rademaker KJ, Hoogervorst B, Bruinse HW 1998 Antenatal onset of haemorrhagic and/or ischaemic lesions in preterm infants: prevalence and associated obstetric variables. Arch Dis Child Fetal Neonatal Ed 78:F51-F56

7. Salhab WA, Perlman JM 2005 Severe fetal acidemia and subsequent neonata encephalopathy in the larger premature infant. Pediatr Neurol 32:25-29

8. Silverman WA, Fertig JW, Berger AP 1958 The influence of the thermal environment upon the survival of newly born premature infants. Pediatrics 22:876-886

9. Day RL, Caliguiri L, Kamenski C, Ehrlich F 1964 Body temperature and survival of premature infants. Pediatrics 34:171-181

10. Buetow KC, Klein SW 1964 Effect of maintenance of "normal" skin temperature on survival of infants of low birth weight. Pediatrics 34:163-170

11. Watkins AM, West CR, Cooke RW 1989 Blood pressure and cerebral haemorrhage and ischaemia in very low birthweight infants. Early Hum Dev 19:103-110

12. Miall-Allen VM, de Vries LS, Whitelaw AG 1987 Mean arterial blood pressure and neonatal cerebral lesions. Arch Dis Child 62:1068-1069

13. Fernandez E, Schrader R, Watterberg K 2005 Prevalence of low cortisol values in term and near-term infants with vasopressor-resistant hypotension. J Perinatol 25:114-118

14. Ng PC, Lee CH, Lam CW, Ma KC, Fok TF, Chan IH, Wong E 2004 Transient adrenocortical insufficiency of prematurity and systemic hypotension in very low birthweight infants. Arch Dis Child Fetal Neonatal Ed 89:F119-F126

15. Chi OZ, Choi YK, Lee DI, Kim YS, Lee I 2001 Intraoperative mild hypothermia does not increase the plasma concentration of stress hormones during neurosurgery. Can J Anaesth 48:815-818

16. Thoresen M, Satas S, Loberg EM, Whitelaw A, Acolet D, Lindgren C, Penrice J, Robertson N, Haug E, Steen PA 2001 Twenty-four hours of mild hypothermia in unsedated newborn pigs starting after a severe global hypoxic-ischemic insult is not neuroprotective. Pediatr Res 50:405-411 
17. Bennet L, Roelfsema V, George S, Dean JM, Emerald BS, Gunn AJ 2007 The effect of cerebral hypothermia on white and grey matter injury induced by severe hypoxia in preterm fetal sheep. J Physiol 578:491-506

18. George S, Scotter J, Dean JM, Bennet L, Waldvogel HJ, Guan J, Faull RL, Gunn AJ 2007 Induced cerebral hypothermia reduces post-hypoxic loss of phenotypic striatal neurons in preterm fetal sheep. Exp Neurol 203:137-147

19. Gluckman PD, Wyatt JS, Azzopardi D, Ballard R, Edwards AD, Ferriero DM, Polin RA, Robertson CM, Thoresen M, Whitelaw A, Gunn AJ 2005 Selective head cooling with mild systemic hypothermia after neonatal encephalopathy: multicenter randomised trial. Lancet 365:663-670

20. Roelfsema V, Gunn AJ, Fraser M, Quaedackers JS, Bennet L 2005 Cortisol and ACTH responses to asphyxia in preterm fetal sheep. Exp Physiol 90:545-555

21. Barlow RM 1969 The foetal sheep: morphogenesis of the nervous system and histochemical aspects of myelination. J Comp Neurol 135:249-262

22. McIntosh GH, Baghurst KI, Potter BJ, Hetzel BS 1979 Foetal brain development in the sheep. Neuropathol Appl Neurobiol 5:103-114

23. Challis JR, Brooks AN 1989 Maturation and activation of hypothalamic-pituitary adrenal function in fetal sheep. Endocr Rev 10:182-204

24. Bennet L, Booth LC, Ahmed-Nasef N, Dean JM, Davidson J, Quaedackers JS, Gunn AJ 2007 Male disadvantage? Gender and fetal cardiovascular responses to asphyxia in preterm fetal sheep. Am J Physiol Regul Integr Comp Physiol 2007;293:R1280-R1286

25. Fraser M, Matthews SG, Braems G, Jeffray T, Challis JR 1997 Developmental regulation of preproenkephalin (PENK) gene expression in the adrenal gland of the ovine fetus and newborn lamb: effects of hypoxemia and exogenous cortisol infusion. J Endocrinol 155:143-149

26. Antonawich FJ, Miller G, Rigsby DC, Davis JN 1999 Regulation of ischemic cell death by glucocorticoids and adrenocorticotropic hormone. Neuroscience 88:319325

27. Mellor DJ, Diesch T, Gunn AJ, Bennet L 2005 The importance of 'awareness' for understanding fetal pain. Brain Res Brain Res Rev 49:455-47
28. Bennet L, Roelfsema V, Dean J, Wassink G, Power GG, Jensen EC, Gunn AJ 2007 Regulation of cytochrome oxidase redox state during umbilical cord occlusion in preterm fetal sheep. Am J Physiol Regul Integr Comp Physiol 292:R1569-R1576

29. Thoresen M, Haaland K, Loberg EM, Whitelaw A, Apricena F, Hanko E, Steen PA 1996 A piglet survival model of posthypoxic encephalopathy. Pediatr Res 40:738748

30. Gagnon R, Murotsuki J, Challis JR, Fraher L, Richardson BS 1997 Fetal sheep endocrine responses to sustained hypoxemic stress after chronic fetal placental embolization. Am J Physiol 272:E817-E823

31. Gardner DS, Fletcher AJ, Fowden AL, Giussani DA 2001 Plasma adrenocorticotropin and cortisol concentrations during acute hypoxemia after a reversible period of adverse intrauterine conditions in the ovine fetus during late gestation. Endocrinology 142:589-598

32. Goldstein DS, Frank SM 2001 The wisdom of the body revisited: the adrenomedullary response to mild core hypothermia in humans. Endocr Regul 35:3-7

33. Myers DA, Robertshaw D, Nathanielsz PW 1990 Effect of bilateral splanchnic nerve section on adrenal function in the ovine fetus. Endocrinology 127:2328-2335

34. Young IR, Loose JM, Kleftogiannis F, Canny BJ 1996 Prostaglandin E2 acts via the hypothalamus to stimulate ACTH secretion in the fetal sheep. J Neuroendocrinol $8: 713-720$

35. Zambrano E, Nathanielsz PW, McDonald TJ 2001 Prenatal and postnatal ovine adrenal cell responses to prostaglandin E(2). J Soc Gynecol Investig 8:149157

36. Panaretto BA, Vickery MR 1970 The rates of plasma cortisol entry and clearance in sheep before and during their exposure to a cold, wet environment. J Endocrinol 47:273-285

37. Tangalakis K, Coghlan JP, Crawford R, Hammond VE, Wintour EM 1990 Steroid hydroxylase gene expression in the ovine fetal adrenal gland following ACTH infusion. Acta Endocrinol (Copenh) 123:371-377 